\title{
ALD $\mathrm{TiO}_{2}$ thin film as dielectric for $\mathrm{Al} / \mathrm{p}-\mathrm{Si}$ Schottky diode
}

\author{
SEFA B K AYDIN ${ }^{a}$, DILBER E YILDIZ ${ }^{\mathrm{b}}$, HATICE KANBUR ÇAVUŞ Ş,* and RECEP ŞAHINGÖZZ $^{\mathrm{a}}$ \\ ${ }^{a}$ Department of Physics, Faculty of Arts and Sciences, Bozok University, Yozgat 66100, Turkey \\ ${ }^{b}$ Department of Physics, Faculty of Arts and Sciences, Hitit University, Çorum 19030, Turkey
}

MS received 14 November 2013; revised 23 February 2014

\begin{abstract}
Electrical analysis of $\mathrm{Al} / \mathrm{p}$-Si Schottky diode with titanium dioxide $\left(\mathrm{TiO}_{2}\right)$ thin film was performed at room temperature. The forward and reverse bias current-voltage $(I-V)$ characteristics of diode were studied. Using thermionic emission (TE) theory, the main electrical parameters of the $\mathrm{Al} / \mathrm{TiO}_{2} / \mathrm{p}$-Si Schottky diode such as ideality factor $(n)$, zero bias barrier height $\left(\phi_{\mathrm{Bo}}\right)$ and series resistance $\left(R_{\mathrm{S}}\right)$ were estimated from forward bias $I-V$ plots. At the same time, values of $n, \phi_{\mathrm{Bo}}$ and $R_{\mathrm{S}}$ were obtained from Cheung's method. It was shown that electrical parameters obtained from TE theory and Cheung's method exhibit close agreement with each other. The reverse-bias leakage current mechanism of $\mathrm{Al} / \mathrm{TiO}_{2} / \mathrm{p}$-Si Schottky barrier diodes was investigated. The $I-V$ curves in the reverse direction are taken and interpreted via both Schottky and Poole-Frenkel effects. Schottky effect was found to be dominant in the reverse direction. In addition, the capacitance-voltage $(C-V)$ and conductance-voltage $(G / w-V)$ characteristics of diode were investigated at different frequencies $(50-500 \mathrm{kHz})$. The frequency dependence of interface states density was obtained from the Hill-Coleman method and the voltage dependence of interface states density was obtained from the high-low frequency capacitance method.
\end{abstract}

Keywords. $\quad \mathrm{ALD} \mathrm{TiO}_{2}$; electrical properties; interface state density; Schottky effect; Poole-Frenkel emission.

\section{Introduction}

Recently, titanium dioxide $\left(\mathrm{TiO}_{2}\right)$ has great importance because of its high dielectric constant, high thermal stability, large band gap, high refractive index and low leakage current density. It has potential applications such as catalysis, sensors, antireflection coating, solar cells and Schottky diodes (Kadoshima et al 2003; Pakma et al 2008, 2009, 2011; Kinac1 et al 2012; Landmann et al 2012; Nasim et al 2012; Rathee et al 2012; Sekhar et al 2012; Sönmezoğlu and Akın 2012). $\mathrm{TiO}_{2}$ are fabricated by various techniques such as chemical vapor deposition, electron beam evaporation, the sol-gel method, sputtering, atomic layer deposition (ALD) method, etc. Among them, the ALD technique has been employed to grow ultra-thin and high- $k$ dielectrics on a substrate owing to its advantages over other deposition methods such as excellent thickness uniformity over large substrate areas, low processing temperature, low impurity content and completely precise thickness control (Lu et al 2006; Xuan et al 2006; Shahrjerdi et al 2007; Wu et al 2007; Hoogeland et al 2009).

Metal-semiconductor (MS) and metal-insulator-semiconductor (MIS) Schottky diodes have an important role in the integrated device technology (Pakma et al 2008, 2009, 2011; Kınacı et al 2012; Sönmezoğlu and Akın 2012). The current-transport mechanisms in these devices are dependent on a variety of factors such as fabrication parameters of semiconductors, formation of insulator layer, device

*Author for correspondence (hatice.kanbur@bozok.edu.tr) temperature and bias voltage, etc. There are various models such as thermionic emission (TE), thermionic field emission (TFE), recombination generation, multistep tunneling compete, Poole-Frenkel and space charge limited-conduction (SCLC) mechanisms to explain charge transport mechanisms and generally, one of them may dominate. However, two and more mechanisms could be used together at certain special conditions. But a complete description of conduction mechanisms through Schottky contact is still a challenging problem. Therefore, the analysis of forward and reverse current mechanisms is important.

In this paper, we have investigated characteristics of $I-V, C-V$ and $G / w-V$ of $\mathrm{Al} / \mathrm{TiO}_{2} / \mathrm{p}-\mathrm{Si}$ Schottky diode. We have discussed the reverse and forward current conduction mechanisms of $\mathrm{Al} / \mathrm{TiO}_{2} / \mathrm{p}$-Si Schottky diode and Schottky diode parameters such as $\phi_{\mathrm{Bo}}, n, R_{\mathrm{s}}$ and $N_{\mathrm{ss}}$ are determined.

\section{Experimental}

$\mathrm{Al} / \mathrm{TiO}_{2} / \mathrm{p}$-Si Schottky diodes used were fabricated using p-type (boron-doped) single-crystal silicon wafer with $\langle 111\rangle$ surface orientation, having a thickness of $300 \mu \mathrm{m}$ and a resistivity of $5-10 \Omega \mathrm{cm}$. For the fabrication process, the $\mathrm{Si}$ wafer was degreased in an organic solvent of $\mathrm{CHClCCl}_{2}$, $\mathrm{CH}_{3} \mathrm{COCH}_{3}$ and $\mathrm{CH}_{3} \mathrm{OH}$; etched in a sequence of $\mathrm{H}_{2} \mathrm{SO}_{4}$ and $\mathrm{H}_{2} \mathrm{O}_{2}, 20 \% \mathrm{HF}$ and a solution of $6 \mathrm{HNO}_{3}: 1 \mathrm{HF}: 35 \mathrm{H}_{2} \mathrm{O}$, $20 \% \mathrm{HF}$; and finally quenched in de-ionized water with a resistivity of $18 \mathrm{M} \Omega \mathrm{cm}$ for a prolonged time. High purity (99.999\%) aluminum (Al) with a thickness of $2000 \AA$ was 
thermally evaporated from the tungsten filament onto the whole backside of half of a wafer at a pressure of $\sim 10^{-6}$ Torr. Low-resistance ohmic contacts were formed by thermal annealing at $400{ }^{\circ} \mathrm{C}$ for $5 \mathrm{~min}$ in flowing $\mathrm{N}_{2}$ in a quartz tube furnace. After ohmic contact, a layer of $\mathrm{TiO}_{2}$ was grown on the $\mathrm{Si}$ substrate by atomic layer deposition (ALD) technique (George et al 1994, 1996; Lu et al 2006; Xuan et al 2006; Shahrjerdi et al 2007; Wu et al 2007; Hoogeland et al 2009) by high-vacuum ALD Savannah S300 system. Immediately after $\mathrm{TiO}_{2}$ growth on Si wafer, Al (99.999\%) with a thickness of $2000 \AA$ was thermally evaporated from the tungsten filament onto the $\mathrm{TiO}_{2}$ surface through metal shadow masks with circular dots of $\sim 2 \mathrm{~mm}$ diameter. Finally, $\mathrm{Al} / \mathrm{TiO}_{2} /$ p-Si Schottky contacts were formed. The energy level and schematic diagram of $\mathrm{Al} / \mathrm{TiO}_{2} / \mathrm{p}-\mathrm{Si}$ Schottky diode are presented in figure 1(a) and (b), respectively. The metal thickness layer and deposition rates were monitored with the help of quartz crystal thickness monitor. The quartz crystal thickness monitor is used to record the metal thickness layer and deposition rates.

Albeit, ALD is a surface controlled layer-by-layer process for the deposition of thin film with atomic layer accuracy, we controlled $\mathrm{TiO}_{2}$ thick with UCF Stylus Profilometer. The $\mathrm{TiO}_{2}$ thick was measured at about $25 \AA$. The $I-V$, $C-V$ and $G / w-V$ characteristics of $\mathrm{Al} / \mathrm{TiO}_{2} / \mathrm{p}-\mathrm{Si}$ diode was measured at room temperature by the Keithley 4200 UCF Semiconductor Parameter Analyzer.
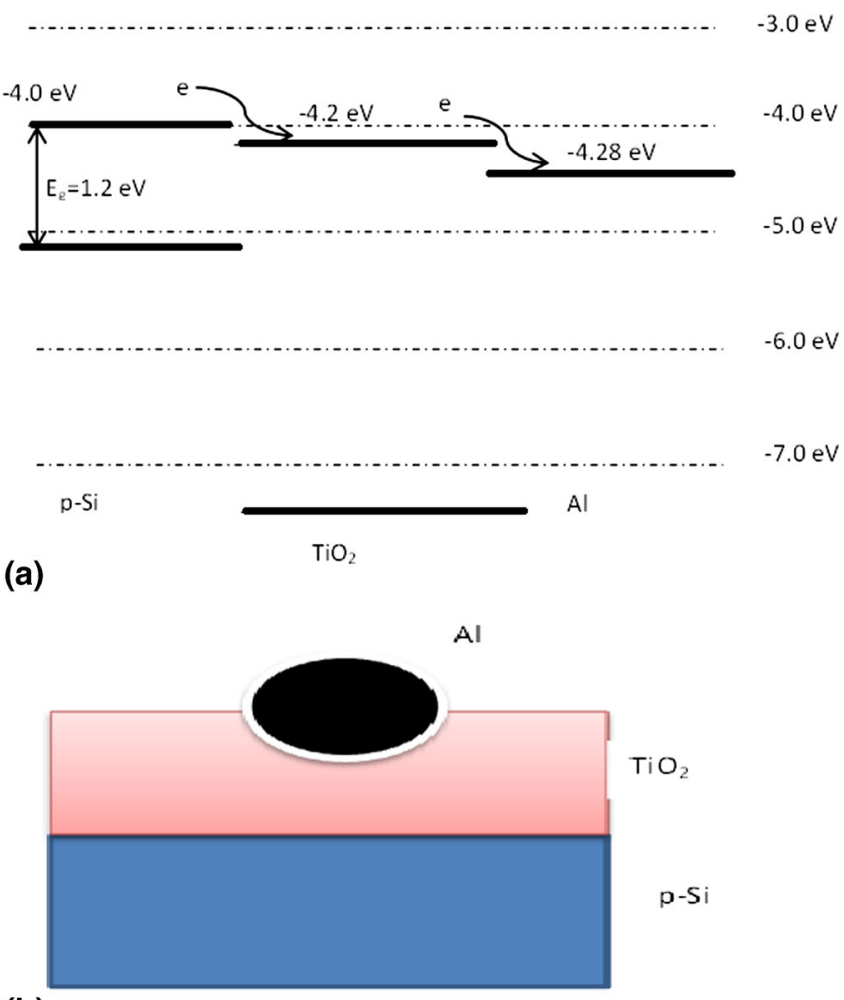

$\mathrm{TiO}_{2}$

$\mathrm{p}-\mathrm{Si}$

(b)

Figure 1. (a) Energy level diagram and (b) schematic diagram of $\mathrm{Al} / \mathrm{TiO}_{2} / \mathrm{p}-\mathrm{Si}$ Schottky diode.

\section{Results and discussion}

\subsection{Forward and reverse bias I-V characteristics}

Figure 2 shows the experimental semi-log forward and reverse bias $I-V$ characteristics of $\mathrm{Al} / \mathrm{TiO}_{2} / \mathrm{p}-\mathrm{Si}$ Schottky diodes at room temperature. As can be seen in figure 2, $\mathrm{Al} / \mathrm{TiO}_{2} / \mathrm{p}-\mathrm{Si}$ Schottky diode exhibits rectifying behaviour. In forward bias $I-V$ characteristics of Schottky contacts, the relationship between the applied-bias voltage $(V \geq 3 k T / q)$ and the current according to thermionic emission (TE) theory is given by (Sze 1981; Rhoderick and Williams 1988; Güllü et al 2012; Reddy and Reddy 2012)

$$
I=I_{\mathrm{o}} \exp \left(\frac{q\left(V-I R_{\mathrm{s}}\right)}{n k T}\right)\left[1-\exp \left(-\frac{q\left(V-I R_{\mathrm{s}}\right)}{k T}\right)\right],
$$

where $q$ is the electronic charge, $V$ the applied voltage, $R_{\mathrm{S}}$ the series resistance, $n$ the ideality factor, $k$ the Boltzmann constant and $T$ the temperature in Kelvin. $I_{\mathrm{O}}$ is the saturation current and is determined by

$$
I_{\mathrm{o}}=A^{*} A T^{2} \exp \left(-q \phi_{\mathrm{Bo}} / k T\right),
$$

where $A^{*}, A, \phi_{\mathrm{Bo}}$ are the effective Richardson constant (32 $\mathrm{A} \mathrm{cm}^{-2} \mathrm{~K}^{-2}$ for p-type Si) (Sze 1981; Rhoderick and Williams 1988), the area of rectifier contact, the zero-bias barrier height, respectively. The saturation current value $I_{0}$

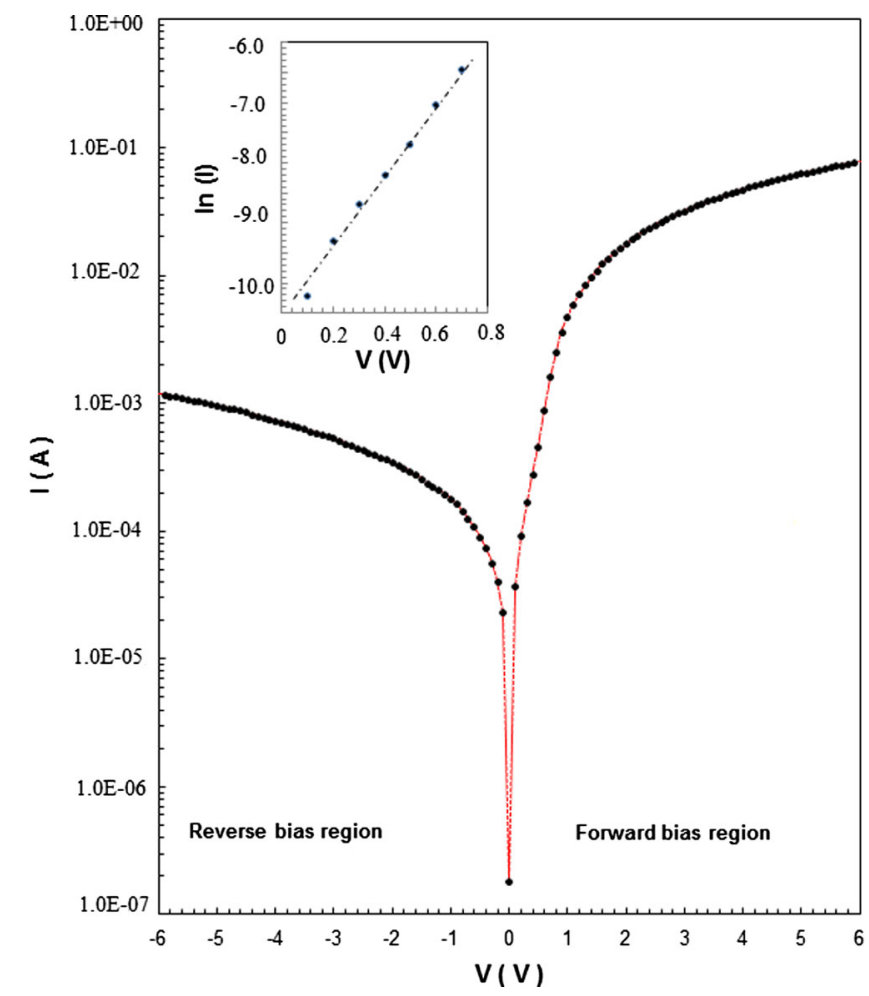

Figure 2. Semi-log current-voltage characteristics of $\mathrm{Al} / \mathrm{TiO}_{2} /$ p-Si Schottky diode. 
was found from the intercept of the linear portion of the forward bias semi-logarithmic $\ln (I)-V$ plot at zero bias. The term $I R_{\mathrm{S}}$ is the voltage drop across the series resistance of the diode.

The value of ideality factor $(n)$ was determined by the linear region of the $\ln (I)-V$ plot (figure 2) and can be written as from (1a)

$$
n=\frac{q}{k T}\left(\frac{\mathrm{d}\left(V-I R_{\mathrm{s}}\right)}{\mathrm{d}(\ln (I))}\right) .
$$

The values of $n$ and $\phi_{\mathrm{Bo}}$ were obtained as 1.80 and $0.66 \mathrm{eV}$, respectively. Normally, it is $n=1$ for an ideal state. Great value of the ideality factor has been attributed to particular distribution of interface states and $\mathrm{TiO}_{2}$ insulator layer between metal and semiconductor (Card and Rhoderick 1971; Janardhanam et al 2012).

The downward bending at adequately high bias voltages was induced by the effect of $R_{\mathrm{S}}$, apart from the existence of the interface states (Pakma et al 2009, 2011; Kinac1 et al 2012). Therefore $n, \phi_{\mathrm{Bo}}$ and $R_{\mathrm{S}}$ were calculated from the Cheung and Cheung (1986) method in the high current range. From (1a), the following functions can be expressed as

$$
\begin{aligned}
& \frac{\mathrm{d} V}{\mathrm{~d}(\ln I)}=n \frac{k T}{q}+R_{\mathrm{s}} I, \\
& H(I)=V-n \frac{k T}{q} \ln \left(\frac{I}{A A^{*} T^{2}}\right)=n \phi_{\mathrm{B}}+R_{\mathrm{s}} I,
\end{aligned}
$$

where $\phi_{\mathrm{B}}$ is the barrier height obtained from data of downward bending region in the forward bias $I-V$ plots. In figure 3 , experimental $\mathrm{d} V / \mathrm{d}(\ln I)$ vs $I$ and $H(I)$ vs $I$ plots are presented for $\mathrm{Al} / \mathrm{TiO}_{2} / \mathrm{p}-\mathrm{Si}$ Schottky diode. As can be given in figure 3, equations (3) and (4) should give a straight line for the data of downward bending region in the forward bias $I-V$ characteristic. Hence, a plot of $\mathrm{d} V / \mathrm{d}(\ln I)$ vs $I$ will give $R_{\mathrm{s}}$ as the slope and $n k T / q$ as the $y$-axis intercept. The $H(I)$ functions were derived by using these $n$ values in (4). The plot of $H(I)$ vs $I$ will also lead to a straight line (figure 3) with a $y$-axis intercept that is equal to $n \phi_{\mathrm{B}}$. The

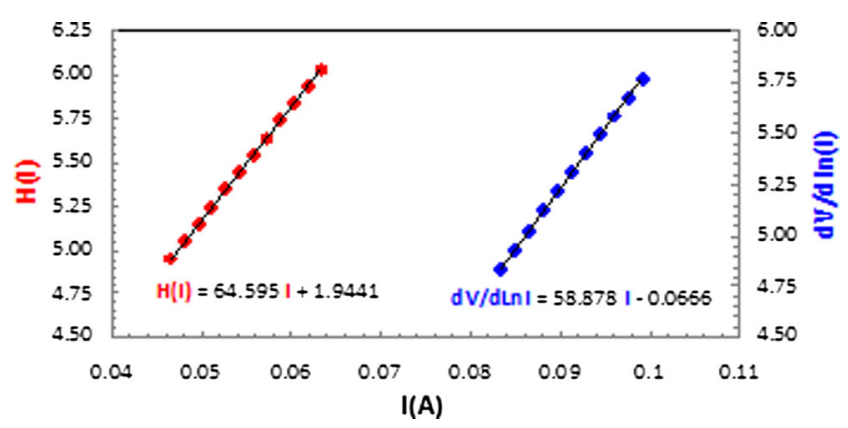

Figure 3. Plots of the $\mathrm{Al} / \mathrm{TiO}_{2} / \mathrm{p}-\mathrm{Si}$ Schottky diode $\mathrm{d} V / \mathrm{d} \ln (I)$ vs $I$ and $H(I)$ vs $I$. slope of $H(I)$ vs $I$ plot also provides a second determination of $R_{\mathrm{s}}$. As shown in table 1 , the values of $n$ and $\phi_{\mathrm{B}}$ obtained from TE theory and Cheung methods are close to each other.

From figure 2, it is evident that the exponential dependence of reverse current $\left(I_{\mathrm{R}}\right)$ strongly suggests that Poole-Frenkel or Schottky barrier lowering mechanisms are operative in the junction. The reverse current-voltage expressions for Poole-Frenkel effect are given as (Soylu et al 2013)

$J_{\mathrm{R}}=J_{\mathrm{o}} \exp \left(\frac{\beta_{\mathrm{PF}}}{k_{\mathrm{B}} T} \sqrt{E}\right)=I_{\mathrm{o}} \exp \left(\frac{\beta_{\mathrm{PF}}}{k_{\mathrm{B}} T d^{1 / 2}} V^{1 / 2}\right)(E=V / d)$.

For the Schottky effect

$$
\begin{aligned}
J_{\mathrm{R}} & =A^{*} T^{2} \exp \left(\phi_{\mathrm{s}} / k T\right) \exp \left(\frac{\beta_{\mathrm{S}}}{k_{\mathrm{B}} T} \sqrt{E}\right) \\
& =A^{*} T^{2} \exp \left(\frac{\beta_{\mathrm{S}}}{k_{\mathrm{B}} T d^{1 / 2}} V^{1 / 2}\right),
\end{aligned}
$$

where $\beta_{\mathrm{PF}}$ and $\beta_{\mathrm{S}}$ are the Poole-Frenkel and Schottky fieldlowering coefficients, respectively.

$$
\beta_{\mathrm{PF}}=2 \beta_{\mathrm{S}}=\left(\frac{q}{\pi \varepsilon_{\mathrm{i}}}\right)^{1 / 2} .
$$

Here, $\varepsilon_{\mathrm{i}}$ is the permittivity of insulator layer $\mathrm{TiO}_{2}$ and $\varepsilon_{\mathrm{i}}=48 \varepsilon_{\mathrm{o}}$ (Lu et al 2006; Xuan et al 2006; Shahrjerdi et al 2007; Wu et al 2007; Hoogeland et al 2009) and $\varepsilon_{\mathrm{o}}$ is the permittivity of free space.

In principle, the Poole-Frenkel and Schottky effects can be distinguished by measured values of field-lowering coefficients $\left(\beta_{\mathrm{PF}}\right)$ is always twice the value of Schottky field coefficients $\left(\beta_{\mathrm{S}}\right)$. The theoretical values of these coefficients for $\mathrm{Al} / \mathrm{TiO}_{2} / \mathrm{p}-\mathrm{Si}$ Schottky contact are $\beta_{\mathrm{PF}}=1.0 \times$ $10^{-4} \mathrm{eV} / \mathrm{m}^{1 / 2} \mathrm{~V}^{-1 / 2}$ and $\beta_{\mathrm{S}}=5 \cdot 48 \times 10^{-5} \mathrm{eV} / \mathrm{m}^{1 / 2} \mathrm{~V}^{-1 / 2}$. Plots of $\ln \left(I_{R}\right)$ vs $E^{1 / 2}$ and $\ln \left(J_{\mathrm{R}} / A^{*} T^{2}\right)$ vs $V^{1 / 2}$ for $\mathrm{Al} / \mathrm{TiO}_{2} / \mathrm{p}-\mathrm{Si}$ Schottky contact at room temperature is shown in figure 4(a) and (b). The experimental value of $\beta$ obtained from slope of linear region in figure $4(\mathrm{a})$ is $4.61 \times$ $10^{-5} \mathrm{eV} / \mathrm{m}^{1 / 2} \mathrm{~V}^{-1 / 2}$ for $300 \mathrm{~K}$. In addition, the experimental value of $\beta_{\mathrm{S}}$ obtained from slope of linear region in figure 4(b) is $3.26 \times 10^{-5} \mathrm{eV} / \mathrm{m}^{1 / 2} \mathrm{~V}^{-1 / 2}$ for diode. The experimentally calculated value of $\beta$ for diode is closer to the theoretical values of $\beta_{\mathrm{S}}$ and therefore Schottky effect is more dominated in reverse direction as the experimentally value of $\beta$ is more close to theoretical Schottky coefficient.

Table 1. Experimental values of parameters obtained from $I-V$ characteristics of $\mathrm{Al} / \mathrm{TiO}_{2} / \mathrm{p}-\mathrm{Si}$ Schottky diode at room temperature.

\begin{tabular}{lcccc}
\hline & $I_{\mathrm{O}}(\mathrm{A})$ & $n$ & $\phi_{\mathrm{Bo}}(\mathrm{eV})$ & $R_{\mathrm{S}}(\Omega)$ \\
\hline $\mathrm{TE}$ & $7.23 \times 10^{-7}$ & 2.96 & 0.66 & - \\
$\mathrm{d} V / \mathrm{d} \ln (I)$ & - & 2.55 & - & 58.88 \\
$H(I)$ & - & - & 0.76 & 64.60 \\
\hline
\end{tabular}




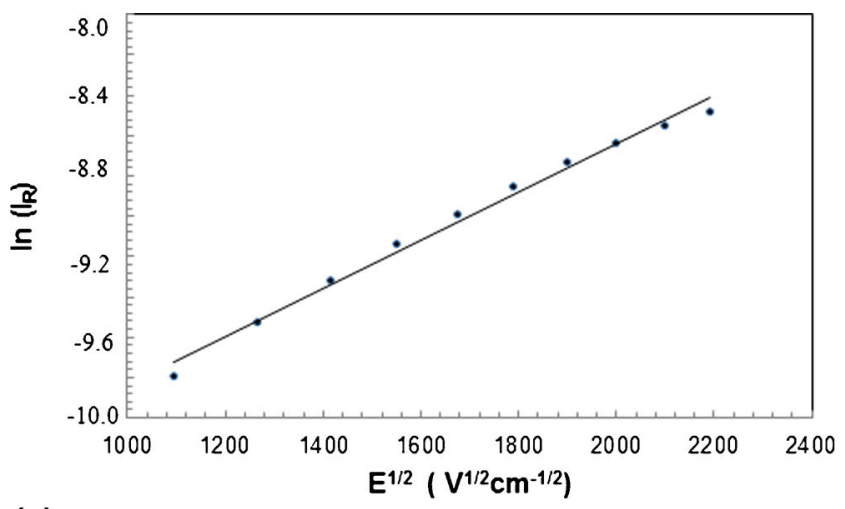

(a)

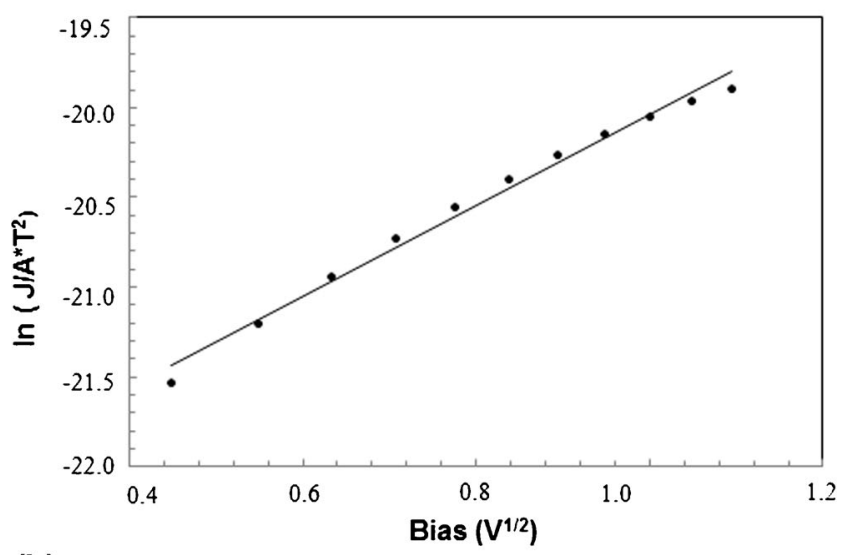

(b)

Figure 4. (a) $\ln \left(I_{\mathrm{R}}\right)$ vs $E^{1 / 2}$ plot and (b) $\ln \left(J_{\mathrm{R}} / A^{*} T^{2}\right)$ vs $V^{1 / 2}$ plot for $\mathrm{Al} / \mathrm{TiO}_{2} / \mathrm{p}-\mathrm{Si}$ Schottky diode.

\subsection{Capacitance-voltage $(\mathrm{C}-\mathrm{V})$ and conductance- voltage $(G / w-V)$ characteristics}

Variations of $C-V$ and $G / w-V$ measurements for $\mathrm{Al} / \mathrm{TiO}_{2} /$ p-Si Schottky diode were performed at different frequencies $(50-500 \mathrm{kHz})$. As can be seen in figure 5(a) and (b), the values of the capacitance and conductance at negative voltages do not change with frequency. However at positive voltages, the values of the capacitance and conductance show an important change with frequency. In figure 5, the values of capacitance give the peaks while conductance almost increases with increasing voltage. The frequency dependence of capacitance and conductance characteristics may be caused by the presence of Schottky barrier, unintentionally doped atoms, the series resistance and interface state density effect. The series resistance and surface states of the Schottky contact are responsible for an abnormal bias dependence of the capacitance and conductance (Sze 1981; Nicollian and Brews 1982; Rhoderick and Williams 1988). At the same time, the values of capacitance and conductance increase with decreasing frequencies because of the fact that at higher frequencies the $N_{\mathrm{ss}}$ cannot follow the ac signal.

The voltage- and frequency-dependent series resistance can be obtained by the data in figure 5(a) and (b) when the

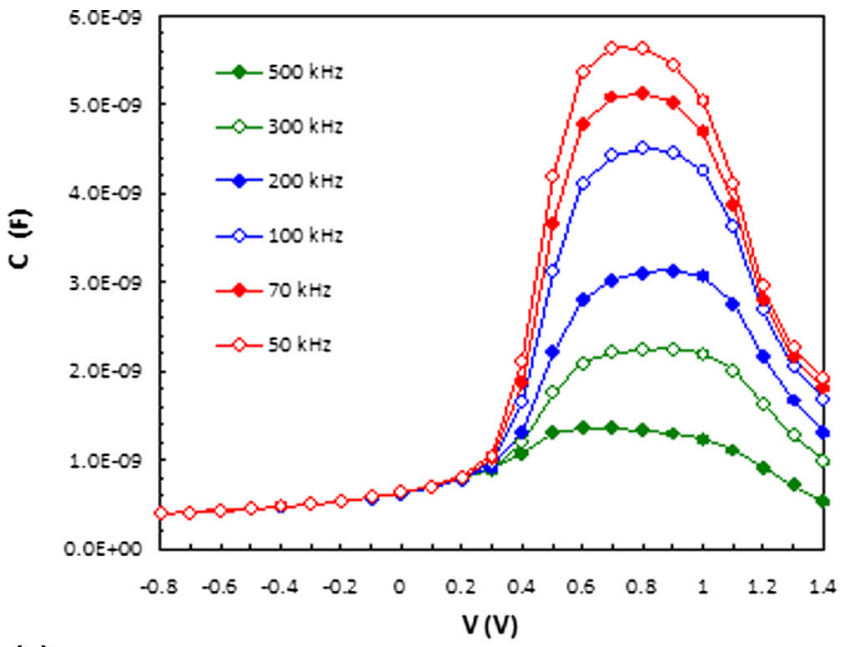

(a)

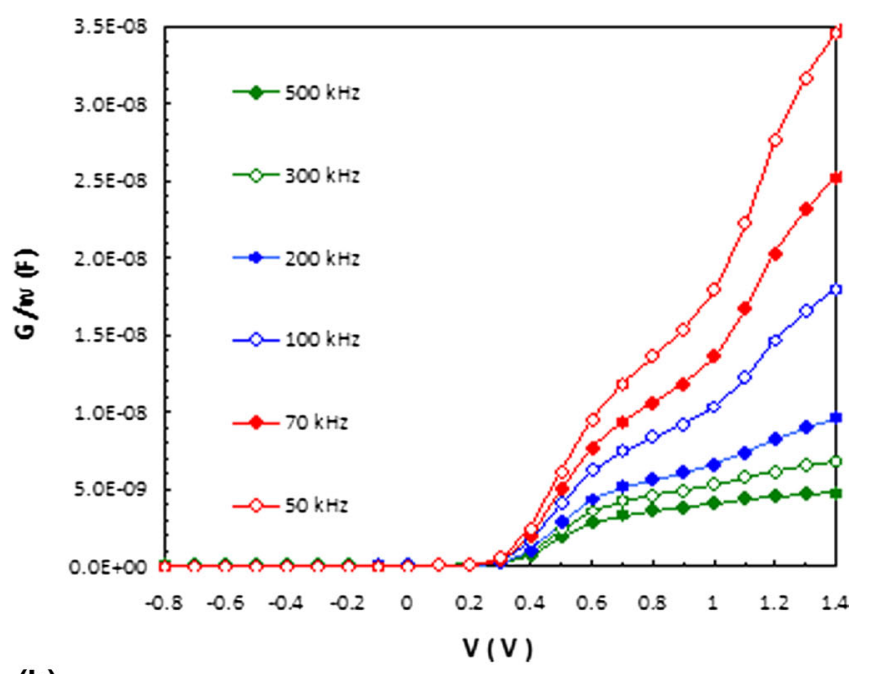

(b)

Figure 5. (a) $C-V$ plots and (b) $G / w-V$ plots for $\mathrm{Al} / \mathrm{TiO}_{2} / \mathrm{p}-\mathrm{Si}$ Schottky diode.

MIS structure is biased into strong accumulation, the admittance $Y_{\mathrm{ma}}$ is given by (Sze 1981; Nicollian and Brews 1982; Rhoderick and Williams 1988)

$$
Y_{\mathrm{ma}}=\left[G_{\mathrm{m}}+j w C_{\mathrm{m}}\right] .
$$

Comparing the real and imaginary parts of admittance, the series resistance of MIS structure is expressed as (Sze 1981; Rhoderick and Williams 1988)

$$
R_{\mathrm{S}}=\frac{G_{\mathrm{ma}}}{G_{\mathrm{ma}}^{2}+\left(\omega C_{\mathrm{ma}}\right)^{2}},
$$

where $C_{\mathrm{ma}}$ and $G_{\mathrm{ma}}$ represent the measured capacitance and conductance in the strong accumulation region.

In figure 6, the values of $R_{\mathrm{S}}$ give the peaks about positive bias where the interface states are intensive. The values of $R_{\mathrm{s}}$ are calculated from the measured capacitance $C_{\mathrm{ma}}$ and 
conductance $G_{\mathrm{ma}}$ at strong accumulation and are given in table 2 for different frequencies.

The frequency dependence of interface states density was obtained from the $C-V$ and $G / w-V$ measurements by using the Hill-Coleman method (Hill and Coleman 1980). In this method, $N_{\mathrm{ss}}$ is given by

$$
N_{\mathrm{ss}}=\left(\frac{2}{q A}\right) \frac{\left(G_{\mathrm{m}} / \omega\right)_{\max }}{\left(\left(G_{\mathrm{m}} / \omega\right)_{\max } C_{\mathrm{ox}}\right)^{2}+\left(1-C_{\max } / C_{\mathrm{ox}}\right)^{2}},
$$

where $A$ is the area of the rectifier contact area of diode, $\omega$ the angular frequency, $C_{\max }$ and $\left(G_{\mathrm{m}} / \omega\right)_{\max }$ the measured $C$ and $G / w$ which correspond to peak values, respectively, and $C_{\mathrm{ox}}$ the capacitance of insulator layer. As can be seen from figure 7 and table 2, the values of $N_{\mathrm{ss}}$ were found to decrease with increasing frequencies. Such behavior of $N_{\mathrm{ss}}$ can be explained on the basis of assumption that only almost all of the interface states cannot follow the applied ac signal sufficiently high frequency (Sze 1981; Nicollian and Brews 1982; Rhoderick and Williams 1988).

The high-low frequency capacitance method is a practical method to obtain interface states density. In this method, the voltage dependence of interface states density was obtained from the high (for this study $500 \mathrm{kHz}$ ) and low (for this

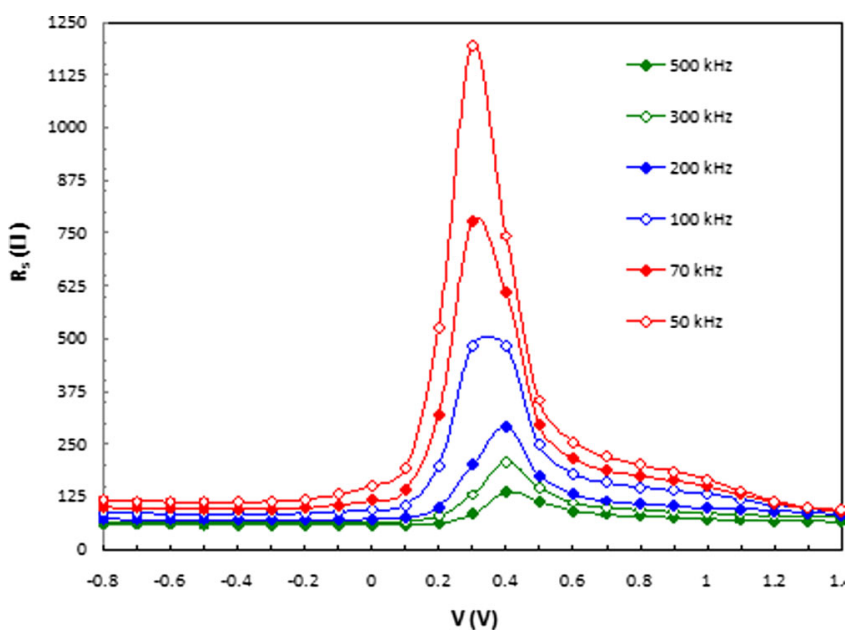

Figure 6. $R_{\mathrm{S}}$ plots of $\mathrm{Al} / \mathrm{TiO}_{2} / \mathrm{p}-\mathrm{Si}$ Schottky diode for different frequencies. study $50 \mathrm{kHz}) C-V$ measurements by using the following relationship (Yıldırım et al 2013):

$$
N_{\mathrm{ss}}=\frac{1}{q A}\left[\left(\frac{1}{C_{\mathrm{LF}}}-\frac{1}{C_{\mathrm{ox}}}\right)^{-1}-\left(\frac{1}{C_{\mathrm{HF}}}-\frac{1}{C_{\mathrm{ox}}}\right)^{-1}\right],
$$

where $C_{\mathrm{LF}}, C_{\mathrm{HF}}$, and $C_{\mathrm{ox}}$ are the low frequency, high frequency, and oxide capacitance, respectively, $q$ the electronic charge and $A$ the rectifying contact area. In figure 8 , the voltage dependence of interface states density is seen.

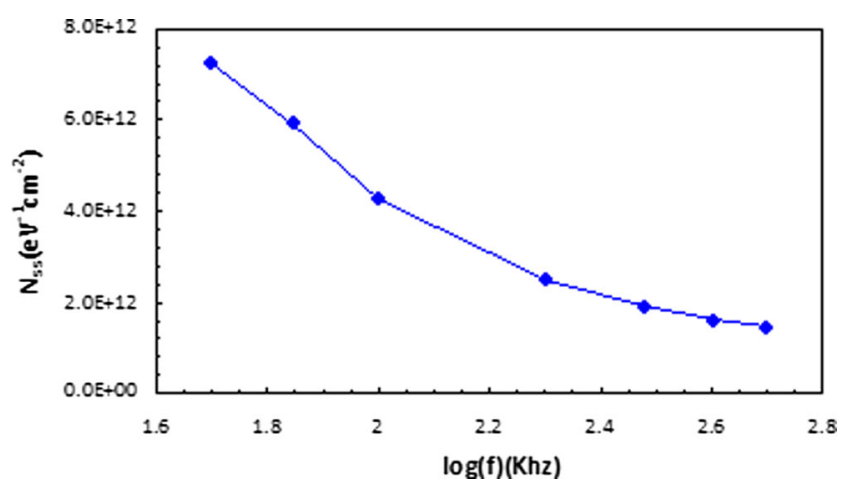

Figure 7. Variation of the interface states density for the $\mathrm{Al} / \mathrm{TiO}_{2} /$ p-Si Schottky diode as a function of the frequency at room temperature.

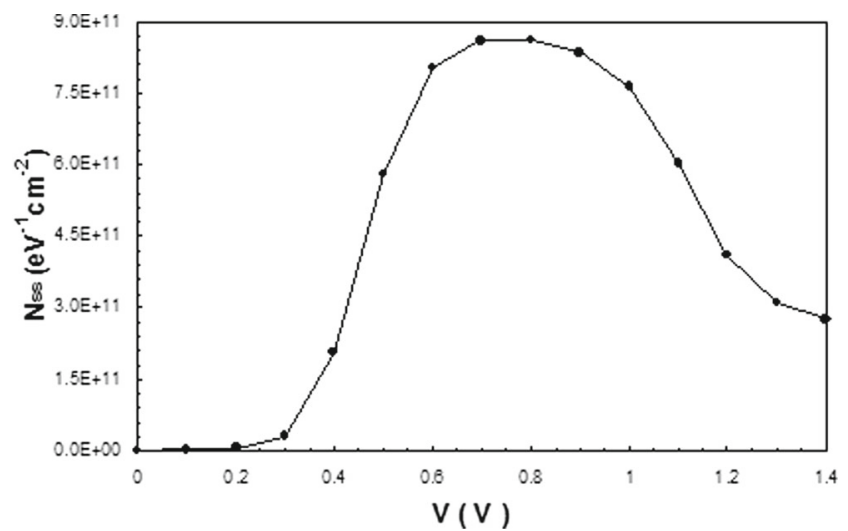

Figure 8. Interface states density versus voltage plot of $\mathrm{Al} / \mathrm{TiO}_{2} /$ p-Si Schottky diode.

Table 2. Experimental values of parameters obtained from $C-V$ characteristics of

\begin{tabular}{|c|c|c|c|c|c|}
\hline$F(\mathrm{kHz})$ & $V_{\max }(\mathrm{V})$ & $C_{\max }(\mathrm{F})$ & $G / w_{\max }(\mathrm{F})$ & $N_{\mathrm{ss}}\left(\mathrm{cm}^{-2} \mathrm{eV}^{-1}\right)$ & $R_{\mathrm{S}}(\Omega)$ \\
\hline 500 & $0 \cdot 6$ & $1.37 \times 10^{-9}$ & $2.84 \times 10^{-9}$ & $1 \cdot 14 \times 10^{12}$ & $63 \cdot 1$ \\
\hline 300 & $0 \cdot 8$ & $2.25 \times 10^{-9}$ & $4.58 \times 10^{-9}$ & $1.84 \times 10^{12}$ & $73 \cdot 6$ \\
\hline 200 & $0 \cdot 8$ & $3.11 \times 10^{-9}$ & $5.64 \times 10^{-9}$ & $2 \cdot 27 \times 10^{12}$ & $77 \cdot 2$ \\
\hline 100 & $0 \cdot 8$ & $4.51 \times 10^{-9}$ & $8.35 \times 10^{-9}$ & $3.38 \times 10^{12}$ & $82 \cdot 1$ \\
\hline 70 & $0 \cdot 8$ & $5 \cdot 13 \times 10^{-9}$ & $1.10 \times 10^{-9}$ & $4.30 \times 10^{12}$ & $83 \cdot 7$ \\
\hline 50 & 0.7 & $5.65 \times 10^{-9}$ & $1.18 \times 10^{-9}$ & $4.81 \times 10^{12}$ & $85 \cdot 4$ \\
\hline
\end{tabular}
$\mathrm{Al} / \mathrm{TiO}_{2} / \mathrm{p}-\mathrm{Si}$ Schottky diode for different frequencies. 


\section{Conclusions}

The conduction mechanism and electronic parameters of $\mathrm{Al} / \mathrm{TiO}_{2} / \mathrm{p}$-Si Schottky diode have been investigated by means of $I-V, C-V$ and $G / w-V$ measurements at room temperature. Using thermionic emission (TE) theory, $n$ is found to be 1.8 and $\phi_{\mathrm{B} o}$ is found to be $0.66 \mathrm{eV}$. The high value of $n$ may be explained on the basis of TE. The reverse bias current density was interpreted in terms of the two field lowering mechanisms, which are Poole-Frenkel and Schottky mechanism. It was seen that the conduction process can be best explained by Schottky effect in the reverse direction.

At the same time, $C-V$ and $G / w-V$ plots of $\mathrm{Al} / \mathrm{TiO}_{2} / \mathrm{p}-\mathrm{Si}$ Schottky diode was analyzed for different frequencies (50-500 kHz). The forward bias $C-V$ plots exhibited an anomalous peak. Such behavior is mainly attributed to the molecular restructuring and reordering of the $N_{\mathrm{ss}}$ and $R_{\mathrm{s}}$. The values of $N_{\mathrm{ss}}$ of the $\mathrm{Al} / \mathrm{TiO}_{2} / \mathrm{p}$-Si Schottky diode were performed by the Hill-Coleman and high-low frequency capacitance method.

\section{Acknowledgements}

This work was partially supported by The Management Unit of Scientific Research Project of Bozok University and Hitit University.

\section{References}

Card H C and Rhoderick E H 1971 J. Phys. D4 1589

Cheung S K and Cheung N W 1986 Appl. Phys. Lett. 4985

George S, Sneh O, Dillon A C, Wise M L, Ott A W, Okada L A and Way J D 1994 Appl. Surf. Sci. 82/83 460

George S M, Ott A W and Klaus J W 1996 J. Phys. Chem. 100 13121

Güllü Ö, Aydoğan S and Türüt A 2012 Thin Solid Films 520 1944
Hill W A and Coleman C C 1980 Solid-State Electron. 23987

Hoogeland D, Jinesh K B, Roozeboom F et al 2009 J. Appl. Phys. 106114107

Janardhanam V, Park Y K, Ahn K S and Choi C J 2012 J. Alloys Compd. 53437

Kadoshima M, Hiratani M, Shimamoto Y, Torii K, Miki H, Kimura S and Nabatame T 2003 Thin Solid Films 424224

Kınacı B, Çetin S Ş, Bengi A and Özçelik S 2012 Mater. Sci. Semicond. Process 15531

Landmann M, Rauls E and Schmidt W G 2012 J. Phys. Condens. Matter 24195503

Lu H L, Sun L Ding S J, Xu M, Zhang D W and Wang L K 2006 Appl. Phys. Lett. 89152910

Nasim F, Ali A, Hafizuddin M and Bhatti A S 2012 J. Appl. Phys. 112044513

Nicollian E H and Brews J R 1982 MOS (metal/oxide/semiconductor) physics and technology (New York: Wiley)

Pakma O, Serin N, Serin T and Altındal Ş 2008 J. Appl. Phys. 104 014501

Pakma O, Serin N, Serin T and Altındal Ş 2009 Sol-Gel Sci. Technol. $\mathbf{5 0} 28$

Pakma O, Serin N, Serin T and Altındal Ş 2011 Physica B 406771

Rathee D, Kumar M and Arya S K 2012 Solid-State Electron. 7671

Reddy N N K and Reddy V R 2012 Bull. Mater. Sci. 3553

Rhoderick E H and Williams R H 1988 Metal semiconductor contacts (Oxford: Clarendon) 2nd edn

Sekhar M C, Kondaiah P, Chandra S V J, Rao G M and Uthanna S 2012 Surf. Interface Anal. 441299

Shahrjerdi D, Tutuc E and Banerjee S K 2007 Appl. Phys. Lett. 91 063501

Sönmezoğlu S and Akın S 2012 Curr. Appl. Phys. 121372

Soylu M, Al-Hartomy, Said S A F, Al-Ghamdi A A, Yahia I S and Yakuphanoglu F 2013 Microelectron. Reliab. 531901

Sze S M 1981 Physics semiconductor devices (New York: John Wiley and Sons) 2nd edn

Wu Y Q, Shen T and Ye P D 2007 Appl. Phys. Lett. 90143504

Xuan Y, Ye P D and Lin H C 2006 Appl. Phys. Lett. 89132103

Yıldırım M, Durmuş P and Altındal Ş 2013 Chin. Phys. B 22 108502 